\title{
Determination of iron content in iron powder used for fireworks and firecrackers based on Energy Dispersive X-ray Fluorescence Spectrometry (EDXRF)
}

\author{
Wu Jun-yi ${ }^{1, a}$, Yang Ying-qiang ${ }^{2, b}$, Qin jia ${ }^{3, c}$ \\ ${ }^{1}$ Technical Center for Dangerous Goods Testing of Guangxi Entry-Exit Inspection and Quarantine Bureau, \\ Beihai, Guangxi, China \\ ${ }^{2}$ Beihai Administration of Work Safety \\ ${ }^{3}$ Guangxi Nongken sugar industry group Limited by Share Ltd \\ ajohnny-woo@vip.163.com, bjohsonbh@sina.com, 2651647174@qq.com
}

Keywords: fireworks and firecrackers; iron powder; iron content; determination; Energy Dispersive X-ray Fluorescence Spectrometry; EDXRF.

\begin{abstract}
Methods used for the determination of iron content in iron powder are mostly based on traditional chemical method, which is lengthy and cumbersome. If inductively coupled plasma emission spectrometry or atomic absorption spectrometry are used to determine the iron with high content, the sample solution must be highly diluted, and it must produce errors in measurement and calling into question the reliability of the data. The method mentioned in this paper is about the determination of iron content in iron powder used for fireworks and firecrackers based on energy dispersive X-ray fluorescence spectrometry by controlling matrix effects between elements. Using sample solution of iron powder in specific concentrates, the iron content can be determined by the specific calibration curve established with an intensity calibration. This method can provide high accuracy and good precision in a short time with a simple process by efficiently controlling the matrix effects. It can fully meet the requirements for the determination of iron in iron powder used for different kinds of fireworks and firecrackers around the world, and it has good generalization and practicability. The average recovery of the method can be $98.07 \% \sim 99.70 \%$, allowing for a difference of $0.5 \%$.
\end{abstract}

\section{Introduction}

In China, fireworks and firecrackers are very important consumer recreational products in people's everyday life since ancient times. Gorgeous colors produced by fireworks and firecrackers are even the iron ing role of foiling festal atmosphere in every grand holiday celebrations. In recent years, with the rapid development of global trade, fireworks and firecrackers are becoming more and more popular all over the world, more and more consumers are fascinatedby different kinds of patterns, pictures, and sound effects of fireworks and firecrackers. Iron element is commonly found in iron powder as primary content used for pyrotechnics, and the price of iron powder depends on the iron content. Quantitative analysis method of the iron content reported in current literature is limited to traditional chemical analysis, such methods have the following disadvantages:(1) Long detecting period. Generally, it will take a skilled technician two whole days or so to complete the detection.(2) The operation is more complicated. It needs to go through many steps such as dissolving sample, filtration, precipitation collection, drying and weighing precipitation and ect. Comparing with traditional chemical analysis methods ,this method based on energy dispersive X-ray fluorescence spectrometry(EDXRF) has the advantages of simple operation steps, short period of detection, high accuracy and good precision. 


\section{Theory}

Iron element is commonly found as primary content in chemical materials such as iron powder in pyrotechnics used for fireworks and firecrackers. Statistical analysis shows that iron content in iron powder used for pyrotechnics is between 30\% to 100\%.Concept of the method: considering the weight of the sample is $0.5 \mathrm{~g}$,constant volume is $1 \mathrm{~L}$ and the concentrations of the iron would be controlled in $0.15 \mathrm{~g} / \mathrm{L} \sim 0.50 \mathrm{~g} / \mathrm{L}$ in sample solutions. And it can prove that when the iron content in the solution is in the range of $0.12 \mathrm{~g} / \mathrm{L} \sim 0.60 \mathrm{~g} / \mathrm{L}$, there would be little matrix effects among elements. So we can establish a working curve which contains the iron elements with the content of $0.12 \mathrm{~g} / \mathrm{L} \sim$ $0.60 \mathrm{~g} / \mathrm{L}$ to determine the iron content in the sample solution. In accordance with the relevant safety regulations, the sample was ground into powder of less than 180 micron. Then the sample powder is placed in an oven at $50^{\circ} \mathrm{C}-55^{\circ} \mathrm{C}$ and dried for 4 hours, and then placed into a dryer for cooling down to room temperature. Pretreated sample is fully dissolved in nitric acid and then filtered into volumetric flask as sample solution. The sample solution can be put into the sample cup and placed in the tank of the EDXRF to measure the fluorescence intensity of the iron elements. The actual content of iron element in the sample can be calculated from the concentrations of the iron reading by the working curve.

\section{Experiment section}

\section{Reagents}

Unless otherwise stated, all the reagents should be guaranteed reagents and pure water is secondary grade water as described in ISO 3696(1987). Nitric acid (1+1): mix nitric acid and pure water thoroughly according to the proportion of 1:1. Standard working solution of the iron nitrate: Weigh $0.83 \mathrm{~g}$ high purity iron powder reference materials (accuracy to $0.1 \mathrm{mg}$ ), and put it in a $300 \mathrm{ml}$ beaker, add $50 \mathrm{~mL}$ nitric acid (1+1), heat the beaker and make the sample solution slightly boiling on an electric stove for $20 \mathrm{~min}$. After the solution is cool down to the room temperature, transfer the solution into a $500 \mathrm{ml}$ volumetric flask, add pure water to the scale.Then we can separately pipette the standard working solution of the nitric acid with volume $5 \mathrm{~mL} 、 10 \mathrm{~mL} 、 15 \mathrm{~mL} 、 20 \mathrm{~mL} 、 25 \mathrm{~mL}$ 、 $30 \mathrm{~mL} 、 35 \mathrm{~mL}$ and $40 \mathrm{~mL}$ into eight $100 \mathrm{~mL}$ volumetric flasks which marked from $\mathrm{N}_{1}$ to $\mathrm{N}_{8}$, and add pure water to reach $100 \mathrm{~mL}$ in each volumetric flask, mix thoroughly for later use. Concentrations of the standard working solution in different flasks are shown in Table 1.

Table 1 Fluorescence intensity of series standard working solutions of iron g/L

\begin{tabular}{|c|c|c|}
\hline NO. & Mass concentration $(\mathrm{g} / \mathrm{L})$ & Fluorescence intensity $(\mathrm{cps} / \mathrm{mA})$ \\
\hline $\mathrm{N}_{1}$ & 0.0830 & 161.77 \\
\hline $\mathrm{N}_{2}$ & 0.1661 & 312.46 \\
\hline $\mathrm{N}_{3}$ & 0.2491 & 484.73 \\
\hline $\mathrm{N}_{4}$ & 0.3321 & 636.13 \\
\hline $\mathrm{N}_{5}$ & 0.4152 & 808.25 \\
\hline $\mathrm{N}_{6}$ & 0.4982 & 933.84 \\
\hline $\mathrm{N}_{7}$ & 0.5812 & 1094.45 \\
\hline $\mathrm{N}_{8}$ & 0.6643 & 1205.25 \\
\hline
\end{tabular}

\section{Instrument and apparatus}

Oven with accuracy to $\pm 2^{\circ} \mathrm{C}$. Analytical balance with accuracy to $0.1 \mathrm{mg}$. energy dispersive X-ray fluorescence spectrometer (EDXRF): United States Thermo Fisher (former Thermo Electron Corporation) Company QUANT'X series. 


\section{Operation step}

(1) Weigh the sample of about $0.5 \mathrm{~g}$, accuracy to $0.1 \mathrm{mg}$.

(2) Place the sample into a clean $300 \mathrm{~mL}$ beaker, add $80 \mathrm{~mL}$ nitric acid $(1+1)$ to the beaker, then place the beaker on an electric stove to make the solution boiled for about $20 \mathrm{~min}$. Filter the solution through filter paper to an $0.5 \mathrm{~L}$ volumetric flask, wash the beaker and the filter paper several times with pure water, and make a constant volume with pure water after the filtered solution cooling down to room temperature.

(3) Parameters of the EDXRF instrument parameters are shown in Table 2.

Table 2 Parameters of the EDXRF instrument

\begin{tabular}{|l|l|}
\hline Filter & Thin Pd \\
\hline Collimator & $8.8 \mathrm{~mm}$ \\
\hline Voltage & $20 \mathrm{v}$ \\
\hline Electric current & Auto \\
\hline Analysis time & $50 \mathrm{~s}$ \\
\hline Count rate & Medium \\
\hline Atmosphere & Air \\
\hline Matrix effects & Not considered \\
\hline Energy range & $0 \sim 40 \mathrm{kev}$ \\
\hline Analysis technique & Intensity correction \\
\hline sample thickness & $\geq 15 \mathrm{~mm}$ \\
\hline
\end{tabular}

(4) Calibration (working) curve: according to the requirements of the method and the instrument criteria, we set the instrument to optimum analysis conditions, and adjust it to the best working condition, and determine spectral intensity of the series standard solution from $\mathrm{N}_{1}$ to $\mathrm{N}_{8}$ to establish the calibration (working) curve with the elemental concentrations as independent variable and the spectral intensity as the dependent variable. The linear correlation coefficient of the regression curve should be 0.99 or higher.

(5) Sample determination: determine the fluorescence intensity of the iron in blank solution and every sample solution under the best analysis condition and read the concentrations from the calibration curve according to the spectral intensity.

\section{Results calculation}

Content of the iron element in the sample can be calculated as mass fraction $W$ and its value shown in\% according to the following formula.

$$
\omega=\omega_{0} \times \frac{0.5}{\mathrm{~m}} \times \frac{V}{500}
$$

Where: $\omega_{0}$-the content of the iron in the sample read by the working curve, expressed in \%. $m$-quantity of the sample, expressed in milligrams $(\mathrm{g})$.

$V$-constant volume of the volumetric flask used for the sample solution, expressed in liters $(\mathrm{mL})$.

$\omega$ - the content of the iron in the sample, expressed in \%.

0.5 -assume that quantity of the sample, expressed in milligrams (g).

500-assume that constant volume of the volumetric flask used for the sample solution, expressed in liters(mL).

\section{Results and discussion}

\section{Solvent selection}

Considering the characteristics of the EDXRF spectrometry, this method selects nitric acid as the solvent for the sample instead of some other strong acids such as hydrochloric acid, sulfuric acid, or 
perchloric acid, which are usually recommended in relevant papers. If these strong acids were to be selected as the solvents to dissolve the sample, great amounts of chlorine and sulfur elements would be introduced to the sample solution, and these would make great matrix effects on the iron element and affect the accuracy of the test. On the contrary, if nitric acid are used as the solvents, only the nitrogen elements are introduced to the sample solution. So, the other elements would have little matrix effects on the iron element and can be basically ignored.

\section{Selection of standard solution.}

In order to make the standard solution as consistent as possible with the sample solution, the iron standard solution would be selected to make the working curve. It proved that when the concentration of the iron element is controlled to the range of $0.12 \mathrm{~g} / \mathrm{L} \sim 0.60 \mathrm{~g} / \mathrm{L}$, it would have little matrix effects on the iron element and can be basically ignored. Because the contents of other impurity elements such as aluminum and manganese are all mostly less than the iron element, they would also have little matrix effects on the iron element in the sample solution.

\section{Recovery test}

To assess the accuracy of the method, we used the standard reference substances to do the recovery test. We dissolved the samples and determined the contents of iron in the sample solution. The values of the iron contents we measured are compared with the theoretical ones, and the experimental data is shown in Table 3 below.

Table 3 Recovery test results

\begin{tabular}{|l|l|l|l|l|l|}
\hline NO. & Reference materials & $\begin{array}{l}\text { Reference } \\
\text { Code }\end{array}$ & $\begin{array}{l}\text { Iron content of } \\
\text { nominal (\%) }\end{array}$ & $\begin{array}{l}\text { Iron content of } \\
\text { measurment (\%) }\end{array}$ & $\begin{array}{l}\text { recovery } \\
\text { rate (\%) }\end{array}$ \\
\hline 1 & Iron powder & $\mathrm{Fe} 01$ & 99.9 & 99.6 & 99.70 \\
\hline 2 & Iron powder & $\mathrm{Fe} 02$ & 90.5 & 90.1 & 99.56 \\
\hline 3 & Iron powder & $\mathrm{Fe} 03$ & 80.8 & 80.3 & 99.38 \\
\hline 4 & Iron standard solution & $\mathrm{Fe} 04$ & 70.6 & 70.1 & 99.29 \\
\hline 5 & Iron standard solution & $\mathrm{Fe} 05$ & 61.5 & 61.1 & 99.35 \\
\hline 6 & Iron standard solution & $\mathrm{Fe} 06$ & 50.2 & 49.7 & 99.00 \\
\hline 7 & Iron standard solution & $\mathrm{Fe} 07$ & 40.5 & 40.1 & 99.01 \\
\hline 8 & Iron standard solution & $\mathrm{Fe} 08$ & 35.6 & 35.1 & 98.60 \\
\hline 9 & Iron standard solution & $\mathrm{Fe} 09$ & 30.7 & 30.2 & 98.37 \\
\hline 10 & Iron standard solution & $\mathrm{Fe} 10$ & 25.9 & 25.4 & 98.07 \\
\hline Average (X) & & & & 99.03 \\
\hline standard deviation (S) & & & & 0.51 \\
\hline
\end{tabular}

\section{Conclusions}

Energy dispersive X-ray fluorescence spectrometry (EDXRF) is used to determine the iron content in iron powder used for fireworks and firecrackers, this method is accurate and quick with high accuracy and good precision. When the iron content in the sample is in the range of $25 \% \sim 100 \%$ as mass fraction, the recovery is $98.07 \% \sim 99.70 \%$.The allowable differential value was $0.5 \%$ between two single tests under repeatable conditions. In other word, this method can completely satisfy the requirements of the fireworks and firecrackers industry. 


\section{Acknowledgement}

This work was supported by Guangxi Science and Technology Project(NO. AD17129009) and Beihai Science and Technology Project(NO.201602030 \& NO.201777023).

\section{References}

[1] Leif, H. C.; Allan, A. Determination of sulfur and heavy metals in crude oil and petroleum products by energy-dispersive $\mathrm{x}$-ray fluorescence spectrometry and fundamental parameter approach.Anal. Chem.,53(12),pp.1788-1792,1981.

[2] Fei, H; Pierre, J. V. E. General approach for quantitative energy dispersive X-ray fluorescence analysis based on fundamental parameters. Anal. Chem.,63(20),pp.2237-2244,1991.

[3] Standard test method for determination of lead in paint layers and similar coatings or in substrates and homogenous materials by energy dispersive x-ray fluorescence spectrometry using multiple monochromatic excitation beams,ASTMF2853,American Society for Testing and Materials Publications, 2010.

[4] Standard test method for analysis of uranium and thorium in soils by energy dispersive x-ray fluorescence spectroscopy, ASTM C1255,American Society for Testing and Materials Publications, 2011.

[5] Duan Tiyu, Li Suqing, et al. Jewellery,Determination of precious metal content - Method using X-ray fluorescence spectrometry,China National Recommended Standard: GB/T 18043-2013, China Standards Press: Beijing, 2014.

[6] Leoni. L,Saitta. M, X-ray fluorescence analysis of powder pellets utilizing a small quantity of material, X-ray Spectrom, 3,pp.74-77,1974.

[7] Rose W.I.,Bornhorst T.J.,Sivonen S.J., Rapid high-quality major and trace element analysis of powdered rock by x-ray fluorescence spectrometry, X-ray Spectrom, 15,pp.55-60,1986.

[8] Gy,Pierre M,The analytical and economic importance of correctness in sampling,Anal.Chim.Acta, 190,pp.13-23,1986.

[9] ZHOU Tong-hui ,WANG Er-kang,LU Wan-zhen ect. Handbook in analytical chemistry(second edition), basic knowledge of and safety knowledge(the first volume), China Chemical industry press:pp.568-580,1997. 